\title{
SACRAL INSUFFICIENCY FRACTURES IN THE ELDERLY
}

\author{
I. GOTIS-GRAHAM, L. MCGUIGAN, T. DIAMOND, I. PORTEK, R. QUINN, A. STURGESS, R. TULLOCH
}

From the St George Hospital, Kogarah, Australia

Sacral insufficiency fractures are not uncommon in elderly patients. We have diagnosed 20 cases in a fiveyear period, and have reviewed the clinical records, radiographs, CT and bone scans. We also assessed the degree of osteoporosis by measuring bone density using dual-energy $X$-ray absorptiometry and bone histomorphometry, and monitored the patients' functional outcome.

Bone scans were positive in all 20 patients, CT showed a fracture or sclerosis in 7 of 12 patients and was useful in excluding malignancy. Plain radiographs were the least helpful, showing sclerosis in only 4 of the 20 patients. Involutional osteoporosis with a reduced bone formation rate was the most common underlying cause. Seventeen patients had complete resolution of pain within nine months, and no patient lost independence in daily activities.

Increased awareness of these fractures may help to avoid unnecessary investigation and treatment. Bedrest and analgesia followed by rehabilitation provide good relief of symptoms.

J Bone Joint Surg [Br] 1994; 76-B:882-6.

Received 25 January 1994; Accepted 20 April 1994

Back pain is common in elderly patients, but its cause may be difficult to determine. Vertebral fractures are a well-known cause but the significance of sacral fractures has only recently been recognised.

Our aim was to highlight the importance of sacral insufficiency fracture as a cause of back pain and to ascertain the best techniques available for diagnosis. We

I. Gotis-Graham, MB BS, Research Scholar of the Arthritis Foundation of Australia

School of Pathology, 4th Floor, Wallace Wurth Building, University of New South Wales, Sydney 2052, Australia.

L. McGuigan, MD, FRACP, Senior Staff Specialist in Rheumatology

T. Diamond, MRCP, FRACP, Senior Staff Specialist in Endocrinology

R. Quinn, FRACP, DDU, Staff Specialist in Nuclear Medicine

A. Sturgess, PhD, FRACP, FRCPA, Staff Specialist in Rheumatology

R. Tulloch, RN, Research Assistant in Rheumatology

I. Portek, FRACP, Visiting Medical Officer in Rheumatology

St George Hospital, Gray Street, Kogarah, New South Wales 2217, Australia.

Correspondence should be sent to Dr I. Gotis-Graham.

(C)1994 British Editorial Society of Bone and Joint Surgery $0301-620 \mathrm{X} / 94 / 6871 \$ 2.00$ also sought to determine the predisposing conditions and the degree of disability resulting from these fractures.

\section{PATIENTS AND METHODS}

We reviewed all patients with a diagnosis of sacral insufficiency fracture seen in our rheumatology service from 1988 to 1993 . We excluded all cases of high-energy trauma involving the pelvis, and recorded the age and gender of the patients, any history of falls or minor trauma, the duration of pain before diagnosis, the period in hospital, risk factors for osteoporosis, and other osteoporotic fractures. All plain radiographs, CT scans of the pelvis and ${ }^{99 \mathrm{~m}} \mathrm{Tc}$ bone scans were reviewed. Eighteen of the patients also had measurements of bone mineral density using dual-energy X-ray absorptiometry (DEXA); five patients had bone biopsies.

Patients were examined to discover any predisposing mechanical factors, in particular the presence of scoliosis. All patients were reviewed within six to nine months of the fracture as regards the functional outcome in terms of the severity of back pain, limitations in walking and daily activities, and their degree of independence.

\section{RESULTS}

We reviewed 20 patients (19 female) with sacral insufficiency fractures. Their mean age was 74 years (62 to 87) and the diagnosis was made at a mean of 5 weeks (4 days to 4 months) after the onset of pain.

All 20 had pain as the presenting complaint. In 17 this was mainly in the sacral and buttock region; in three it was low lumbar. Seven patients also had groin pain, all of whom had additional fractures of the ramus or body of the pubis. The pain was of acute onset, severe and aggravated by weight-bearing. Fourteen patients required admission to hospital for a mean of 21 days ( 7 to 44 ) for bed-rest and narcotic analgesics to control the pain.

All the patients had local sacral tenderness on palpation and restriction of low back movements, but there were no related neurological abnormalities. Only nine patients gave a history of trauma and it was always of low energy such as a fall from the standing position on to the buttocks.

Imaging. The most reliable investigation was bone scintigraphy, which was abnormal in all 20 patients. There were four patterns of uptake. The most common, seen in eight, was increased uptake in one ala. Seven patients had 


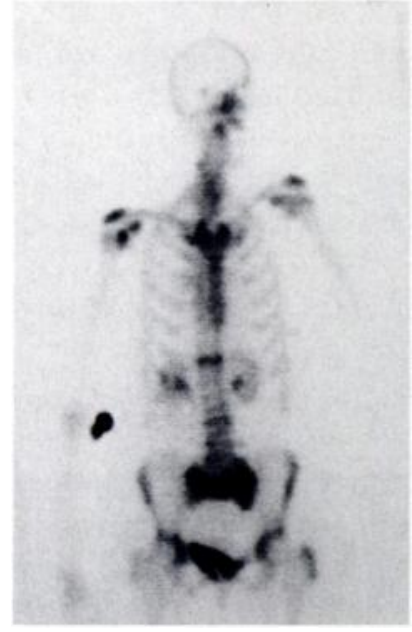

Fig. 1a

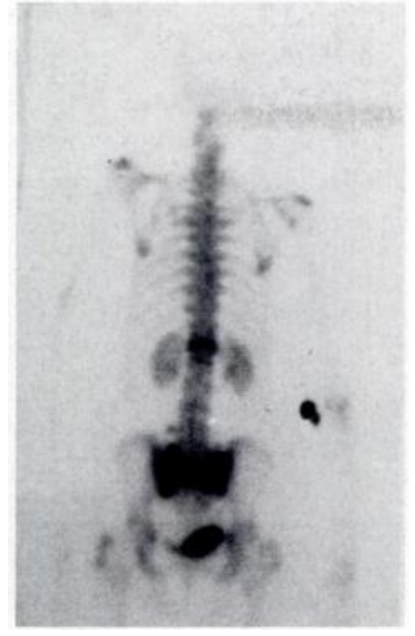

Fig. 1b
Bone scans showing the $\mathrm{H}$-sign. Figure $1 \mathrm{a}-$ Anterior view. Figure $1 \mathrm{~b}-$ Posterior view. This is the characteristic appearance of a sacral insufficiency fracture. uterine malignancy. None had any evidence of metastatic bone disease.

Osteoporosis. Eighteen patients had measurements of bone mineral density using DEXA at three sites: the anteroposterior lumbar spine L2 to L4, lateral L3 and the femoral neck. Seventeen of these had severe osteopenia (Fig. 5). The absolute mean density in the lateral view of the $\mathrm{L} 3$ vertebral body was $0.37 \mathrm{~g} / \mathrm{cm}^{2}$, well below the fracture threshold at this site which has previously been reported as $0.55 \mathrm{~g} / \mathrm{cm}^{2}$ (Smart et al 1992).

Five patients had bone biopsies to exclude metastatic disease, and bone histomorphometry was also performed on these specimens. No metastatic disease was found, but all five had evidence of low-turnover osteoporosis and one had concomitant osteomalacia. The mean trabecular bone area was $14.9 \%$ (age- and sex-matched normal mean value $22 \%$ ), and the bone formation rate was $0.02 \mu \mathrm{m}^{3} /$ $\mu \mathrm{m}^{2}$ /day as against an age- and sex-matched normal mean value of 0.05 (Diamond et al 1989).

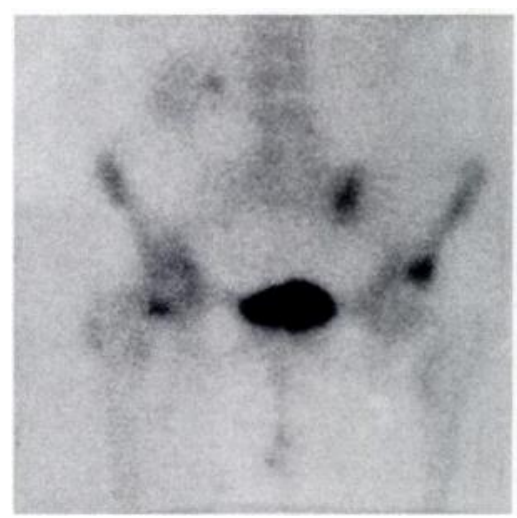

Fig. 2a

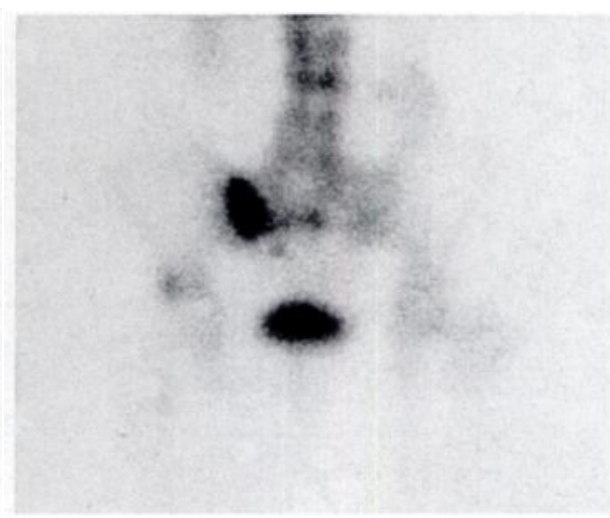

Fig. $2 b$
The bone scan appearances, a) anterior and b) posterior, of a unilateral sacral fracture with associated insufficiency fractures in the neck of the right femur and the left ilium.

the pattern of vertical uptake in both alae with a horizontal component in the body of the sacrum; this is the $\mathrm{H}$ fracture described by Ries (1983). Four patients showed vertical uptake in both alae with no horizontal component. One patient had uptake in one ala with a horizontal component (Figs 1 and 2). CT in 12 of the patients showed a fracture line in five, sclerosis in two (Fig. 3) and normal appearances in five.

Plain radiography was the least helpful investigation, showing sclerosis of the sacrum in only four patients. In two of these the sclerosis was recognised only after the result of the scan was available (Fig. 4). No case showed significant displacement of the sacral fracture.

\section{Predisposing factors}

Medical conditions. Six of the 20 patients had longstanding rheumatoid arthritis, five of whom were under treatment with prednisone in a dose of less than $10 \mathrm{mg}$ per day. Two other patients took maintenance prednisone, one for asthma and the other for polymyalgia rheumatica. One patient had had previous radiotherapy to the pelvis (at a total dose of $45 \mathrm{~Gy}$, given three years previously) for

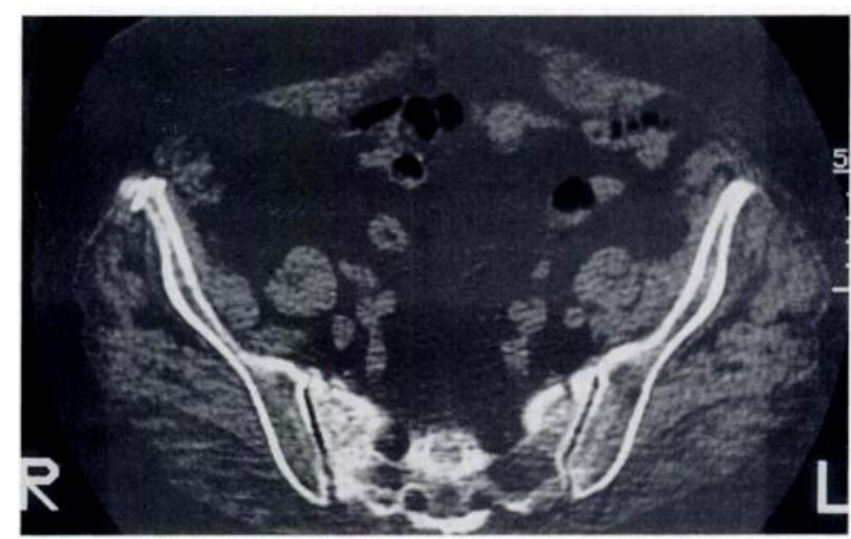

Fig. 3

Pelvic CT scan showing bilateral sacral fractures with interruption of the anterior cortex of the sacral wing (arrows). They extend posteriorly, parallel to the sacroiliac joint and there is associated sclerosis of the right ala.

Mechanical factors. Seven of the patients had moderate lumbar scoliosis. In five of them, the sacral fracture was opposite the convex side of the lumbar scoliosis. 


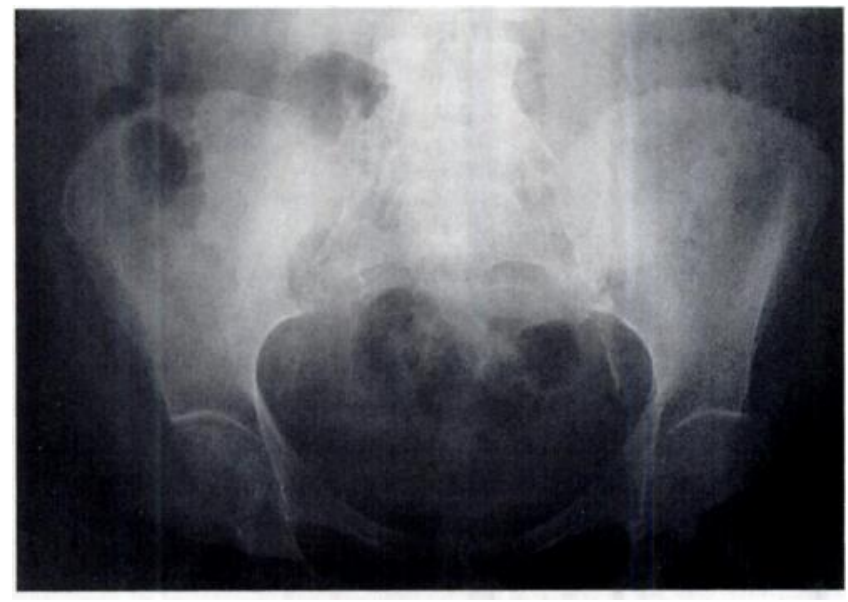

Fig. 4

Pelvic radiograph of a woman with a right sacral insufficiency fracture; there is irregular sclerosis.
(Table I). This relatively small number may be due to lack of awareness that these fractures do occur in the elderly, presenting with low back pain and variable radiation to the buttocks and legs. A history of trauma is usually absent or of a mild nature: a definite injury was reported in 23 of the 110 collected cases and in 9 of our 20 patients.

Bone scintigraphy was the most useful investigation: all our patients showed areas of increased uptake at involved sites, even at initial presentation when plain radiographs and CT were not diagnostic. In cases in which bone scintigraphy did not indicate the characteristic $\mathrm{H}$ fracture we found CT of the pelvis useful in showing the fracture line and excluding any destructive process. Plain radiographs did not help to establish the diagnosis and were sometimes misleading.

In the collected series, 96 of the 110 reports on patients with sacral fractures noted the results of plain

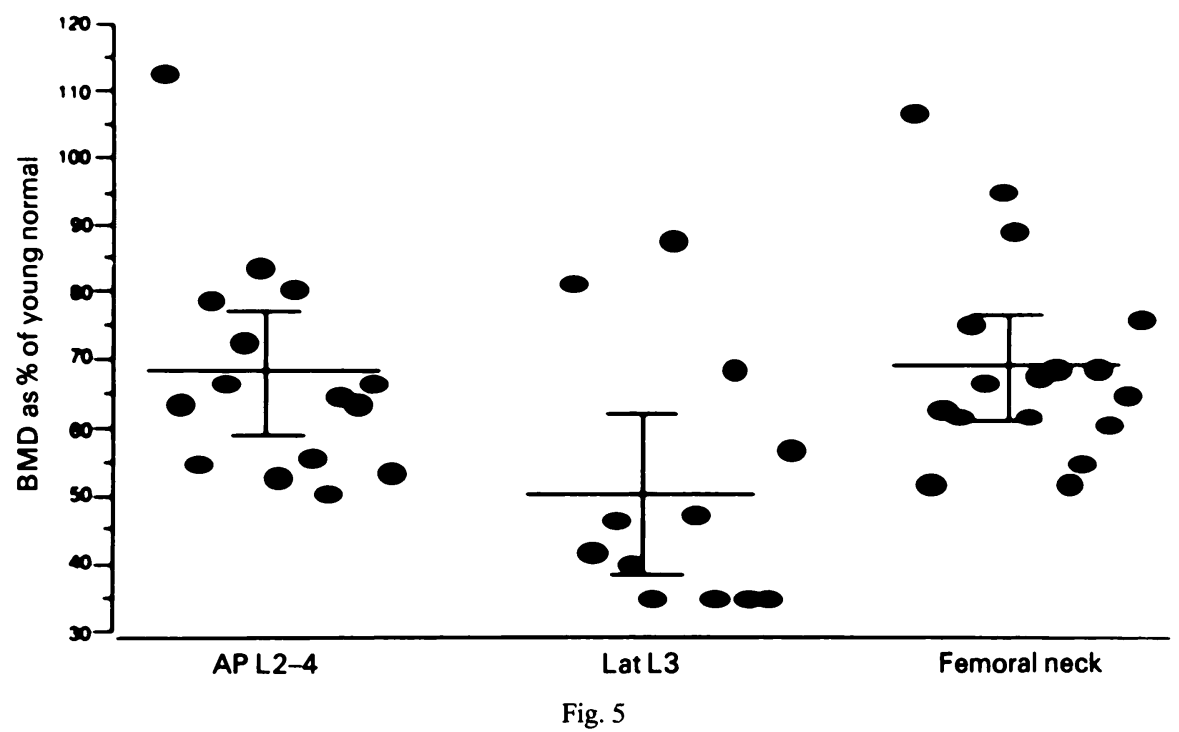

Bone mineral density at three sites in 18 patients with sacral insufficiency fractures. The values are expressed as percentages of those found in young normal subjects. The mean $\pm 1 \mathrm{SD}$ is shown for each site.

Other insufficiency fractures. At the time of the sacral fractures, scintigraphy showed 15 vertebral compression fractures, ten fractures of the pubic rami, five of the hip, four of the head of the humerus, five of the body of the pubis and three of the supra-acetabular ilium.

Functional outcome. At six to nine months' follow-up only three patients required mild analgesics for occasional recurrences of pain and none required narcotic drugs. The other 17 patients had complete resolution of local pain. No patient lost any significant independence in daily living, and all were living in their original accommodation. Two patients used walking sticks and one required help from neighbours in preparing her meals. None had died.

\section{DISCUSSION}

A review of the English literature indicates that only 110 cases of sacral insufficiency fractures have been reported radiography. Fifty-five showed sclerosis and 12 showed a fracture; other imaging modes were needed to confirm the diagnosis. None of our four patients with sclerosis in a sacral ala could be diagnosed solely by plain radiography. Changes in plain radiographs are seen only after fracture union with callus formation, and linear sclerosis may be difficult to detect in an osteoporotic pelvis with its complex bony detail.

Many of our patients were initially presumed to have metastatic disease because of their severe pain, the requirement for narcotic analgesics and the lack of significant trauma. Five required bone biopsies to exclude this diagnosis. Only two of our patients had a history of malignancy (uterus, prostate) but neither had known bone metastases. A much larger proportion of patients, 49 of 110 , in the collected series had a past history of malignancy, mostly gynaecological or colorectal, with no 
离

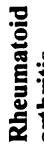

$00-0 n=n n 00 m 0000000$

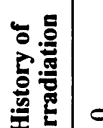

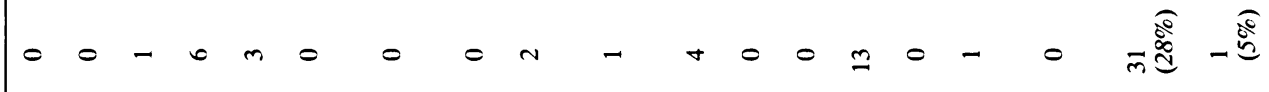

突

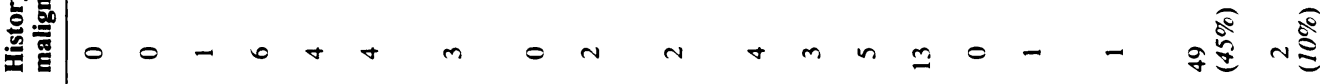

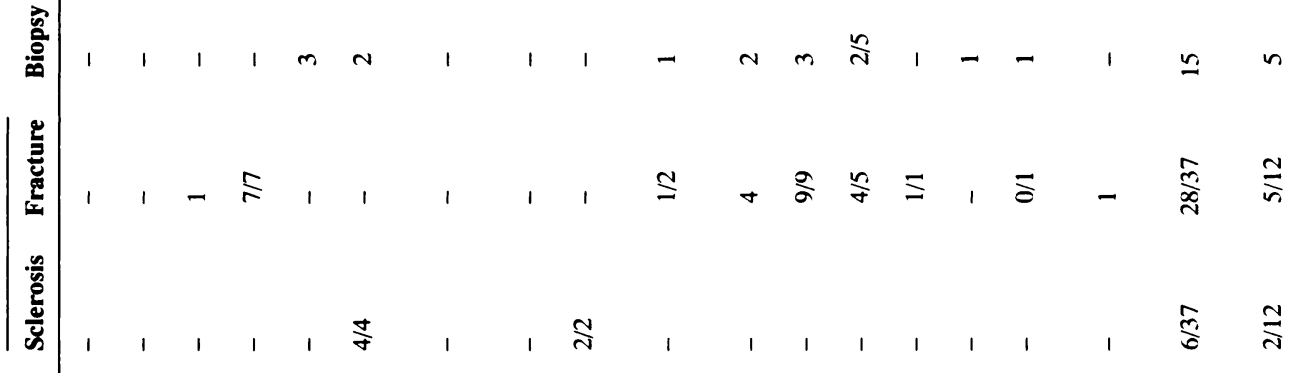

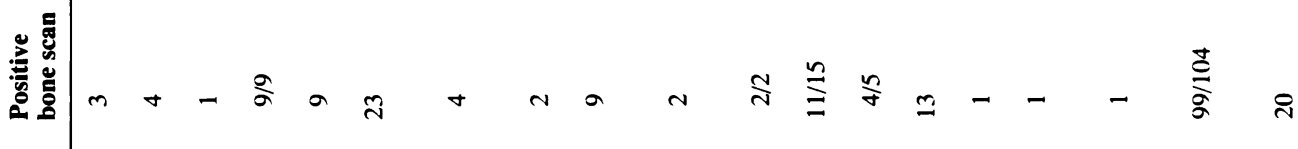

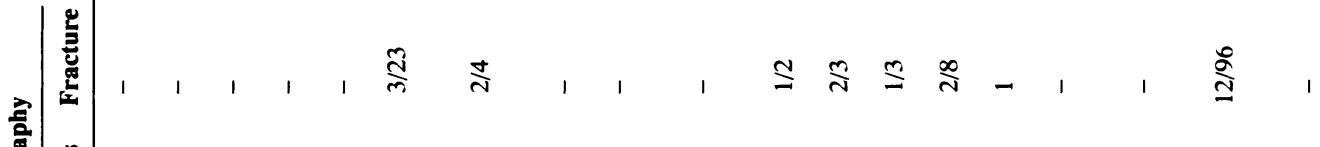

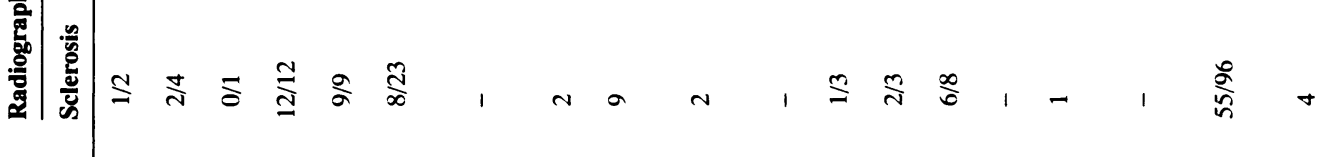

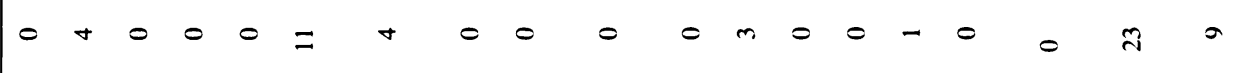

䒿

z远

$m-00000000000--000$

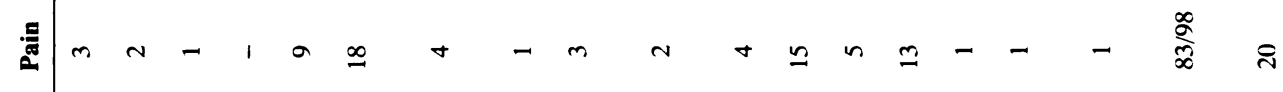

它产

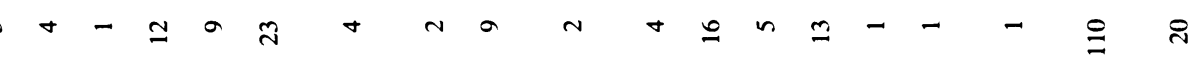

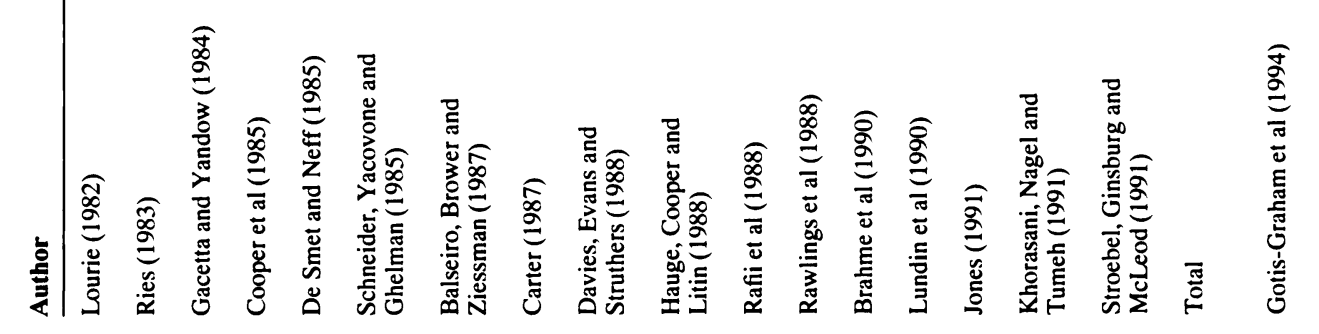


known metastases at the time of fracture. The low prevalence of malignancy in our series may be caused by a selection bias, since suspected cases may have been referred to the oncology service rather than to our rheumatology service.

The dominant predisposing factor appears to be involutional osteoporosis as shown by the low mean lumbar spine bone density. The marked predominance of postmenopausal women in our series was also seen in the collected series (100 of 110 patients). Of our patients, one-third had rheumatoid arthritis or were on maintenance prednisone in a dose less than $10 \mathrm{mg}$ per day. It is not surprising that other insufficiency fractures often accompanied or preceded the sacral fracture, and the high incidence of pubic fractures suggests that these two fractures often occur together. The presence of fractures in both anterior and posterior arches of the pelvis may help to explain the delayed healing that is commonly seen.

Sacral insufficiency fractures are probably related to the important weight-bearing function of the bone; in an upright posture much of the body-weight is transmitted through the spine to the sacroiliac joints. Cooper, Beabout and Swee (1985) considered that the vertical fractures were probably the initial event, occuring parallel to the

\section{REFERENCES}

Balseiro J, Brower AC, Ziessman HA. Scintigraphic diagnosis of sacral fractures. $A J R$ 1987; 148:111-3.

Brahme SK, Cervilla V, Vint V, et al. Magnetic resonance appearance of sacral insufficiency fractures. Skeletal Radiol 1990; 19:489-93.

Carter SR. Stress fracture of sacrum: brief report. J Bone Joint Surg [Br] 1987; 69-B:843-4.

Cooper KL, Beabout JW, Swee RG. Insufficiency fractures of the sacrum. Radiology 1985; 156:15-20.

Davies AM, Evans NS, Struthers GR. Parasymphyseal and associated insufficiency fractures of the pelvis and sacrum. Br J Radiol 1988; 61:103-8.

De Smet AA, Neff JR. Pubic and sacral insufficiency fractures: clinical course and radiologic findings. AJR 1985; 145:601-6.

Diamond TH, Stiel D, Lunzer $\mathbf{M}$, et al. Hepatic osteodystrophy. Gastroenterology 1989; 96:213-21.

Gacetta DJ, Yandow DR. Computed tomography of spontaneous osteoporotic sacral fractures. J Comput Assist Tomogr 1984; 8: 1190-1.

Hauge MD, Cooper KL, Litin SC. Insufficiency fractures of the pelvis that simulate metastatic disease. Mayo Clin Proc 1988; 63:807-12.

Jones JW. Insufficiency fracture of the sacrum with displacement and neurologic damage: a case report and review of the literature. $J \mathbf{A m}$ Geriatr Soc 1991; 39:280-3. sacroiliac joints near the line of the lateral margins of the lumbar vertebrae, which explains the consistent site in all of our patients. Continued or more severe stress may cause a fracture on the contralateral side and the addition of a transverse fracture line. In two of our patients fractures of one sacral ala were followed by fracture of the other side. Mechanical factors such as lumbar scoliosis may cause alterations in weight-bearing through the sacrum and further studies of biomechanical stress are needed to elucidate the mechanisms.

Despite advanced age, significant osteoporosis, and severe pain from sacral and other insufficiency fractures, our patients had an excellent prognosis and became painfree and fully independent within nine months.

Conclusions. Sacral insufficiency fractures are not uncommon in elderly patients and are best diagnosed by ${ }^{99 \mathrm{~m}} \mathrm{Tc}$ scintigraphy. Atypical patterns of uptake may require CT of the pelvis. The underlying cause is involutional osteoporosis with reduced bone formation. Increased awareness of these fractures may help to avoid unnecessary investigation by biopsy or MRI. Conservative management by bed-rest and analgesia followed by rehabilitation leads to an excellent functional outcome.

No benefits in any form have been received or will be received from a commercial party related directly or indirectly to the subject of this article.
Khorasani R, Nagel JS, Tumeh SS. (Radiologic vignette) Sacral insufficiency fracture. Arthritis Rheum 1991; 34:1387-90.

Lourie H. Spontaneous osteoporotic fracture of the sacrum: an unrecognised syndrome of the elderly. J Am Med Assoc 1982; 248:715-7.

Lundin B, Bjorkholm E, Lundell M, Jacobsson H. Insufficiency fractures of the sacrum after radiotherapy for gynaecological malignancy. Acta Oncol 1990; 29:211-5.

Rafii M, Firooznia H, Golimbu C, Horner N. Radiation induced fractures of sacrum: CT diagnosis. J Comput Assist Tomogr 1988; 12:231-5.

Rawlings CE, Wilkins RH, Martinez S, Wilkinson RH Jr. Osteoporotic sacral fractures: a clinical study. Neurosurgery 1988; 22:72-6.

Ries T. Detection of osteoporotic sacral fractures with radionuclides. Radiology 1983; 146:783-5.

Schneider R, Yacovone J, Ghelman B. Unsuspected sacral fractures: detection by radionuclide bone scanning. $A J R$ 1985; 144:337-41.

Smart RC, Diamond T, Bryant C, Butler SP, Rohl P. Clinical importance of lateral spine scans using dual energy X-ray absorptiometry. Aust NZ J Med 1992; 22:414.

Stroebel RJ, Ginsburg WW, McLeod RA. Sacral insufficiency fractures: an often unsuspected cause of low back pain. $J$ Rheumatol 1991; 18:117-9. 